\title{
Risk mitigation in the implementation of AMTs: A guiding framework for future
}

\author{
Bhaskar Nagar* and Tilak Raj
}

Department of Mechanical Engineering, YMCA University of Science \& Technology, Faridabad-121006

\begin{tabular}{|c|c|}
\hline A R T I C L E I N F O & A B S T R A C T \\
\hline $\begin{array}{l}\text { Article history: } \\
\text { Received 20 September } 2011 \\
\text { Received in revised form } \\
\text { November, 2, 2011 } \\
\text { Accepted November, } 32011 \\
\text { Available online } \\
18 \text { November } 2011 \\
\text { Keywords: } \\
\text { AMTs } \\
\text { ISM } \\
\text { Implementation }\end{array}$ & $\begin{array}{l}\text { The fast industrial development increases different types of risks for the industries. Many risk } \\
\text { factors are inherent in the implementation of advanced manufacturing technologies (AMTs). } \\
\text { Industries are developing methodologies for risk prevention and protection. The present } \\
\text { research focuses to identify various risks that could influence the implementation of AMTs, and } \\
\text { develop a framework to mitigate them. For this framework, interpretive structural } \\
\text { modeling(ISM) has been used to depict the relationship and priority among the various risks. } \\
\text { This research provides a path for managers and indicates the dominant risks on the basis of } \\
\text { higher driving power. Also, this research classifies the relationship among various risks in } \\
\text { AMTs implementation according to their driving power and dependence. The risks have been } \\
\text { categorized into four categories as autonomous risks, linkage risks, dependent risks and } \\
\text { independent risks. The proposed hierarchal model would help the management to effectively } \\
\text { handle and develop strategies against the risks and hence new and latest technologies can be } \\
\text { adopted with ease and effectiveness. }\end{array}$ \\
\hline
\end{tabular}

\section{Introduction}

The advanced manufacturing technologies (AMTs) like computer aided design(CAD), computer aided manufacturing(CAM), computer aided engineering(CAE), computer aided process planning(CAPP), computerized numerical controls(CNCs), robotics, reconfigurable manufacturing systems(RMS), computerized production control, computerized inventory control, computerized shop-floor monitoring and control, green manufacturing, lean manufacturing, concurrent engineering, just in time manufacturing, virtual manufacturing, group technology and flexible manufacturing systems(FMS) are attracting the Indian manufacturing industries for their adoption to meet the changing customer demands, challenges imposed by international competition and rapid delivery to market. AMTs offers many advantages over other manufacturing systems like cost reduction, improved flexibility, increased productivity and reduced set-up times (Raj et al., 2008). To achieve those benefits, firms want to the implement these technologies. AMTs are quite different from other technologies because they are more expensive, require more organizational changes and might arouse more resistance to change. Therefore, the implementation process of AMTs is very difficult and risky task in real sense, especially in developing countries like India. Many risks and barriers inhibit its adoption. Therefore, managers should carefully analyze the risks before deciding to introduce the

* Corresponding author Tel: + 919990772988

E-mail: bhasker_nagar@yahoo.com (B. Nagar) 
AMTs and automation into their firms. In the present research work, critical risk factors are identified based on the literature review and expert opinion and their driving power and dependence have been found using interpretive structural modeling (ISM) approach so that strategies can be developed to overcome the risks involved in AMTs adoption and implementation.

Firms adopting AMTs like computer integrated manufacturing, combinational tools and FMS had exerted significantly higher levels of effort on strategic planning and team-based project management and had also achieved higher levels of performance across a wider range of performance factors than other firms. AMT is of enormous strategic importance, as it can improve the effectiveness of manufacturing in terms of cost, quality, flexibility, and lead time (Inman, 1991; Beatty, 1990; Meredith, 1988; Beatty, 1990). AMTs are being adopted to varying degrees and in various combinations, by manufacturing firms around the world. Merely deciding to adopt AMT, however, does not guarantee success; effective implementation is also necessary. In our own experience, the companies have had mixed success in implementing advanced technologies, dovetails with others impressions. While the business press often focuses on success stories, many firms (even those ultimately successful) experience substantial risk in their implementation. These problems are seldom technical but more often comprise a blend of technical, economic, behavioral and political concerns. The strategic potential of AMT can only be fully exploited if these new technologies are effectively implemented, which in turn depends on the quality of the risk analysis in the implementation process. A framework has been presented in this paper to explain how the risks involved in AMT implementation affect project success. It is intended to help managers through this framework avoid the pitfalls and reap the strategic benefits of advanced technology implementation, and to guide future research. The focus of this paper is on various risks that could impact the AMTs implementation and adoption. The major objective is to contribute and provide a better understanding of risk management in AMTs. The main research problems addressed by the study are:

(1) What risks are associated with AMTs implementation and adoption?

(2) How these risks are related with each other?

(3) Which risk factor is having higher driving power and dominance?

(4) What is the direction for future research?

\section{Literature review}

The literature indicates the researcher's consideration for different kinds of risks in wide applications around the world. According to Aven et al. (2007) risk is the combination of possible consequences and associated uncertainties. Thus, the assessment and management of risks require both the probability of risky events and the losses to be understood and identified. This could be performed using semi-quantitative scale (Hallikas et al., 2004). The introduction of various latest tools and techniques enhanced the risk exposure in AMTs. The researchers have performed the risk management in supply chain management (Norrman \& Jansson, 2004, Jhakaria et al., 2005). Speckman and Davis (2004) classify risks into various dimensions like physical dimension, informational dimension, financial dimension, security dimension, relationship dimension and corporate social responsibility dimension.

Harland et al. (2003) provided a list of 11 categories of risks and used four basic approaches that a firm could employ to mitigate risks through a collaborative and coordinated mechanism are supply management, demand management, product management and information management (Tang, 2006). Risks associated with AMTs have a wide variety of impacts. Based on the type of impact that different risks have on the IT based firms, they can be broadly classified as information security/breakdown risks, forecast risks, intellectual property rights risks, and IT/IS outsourcing risks (Faisal et al., 2006b).

Bahli and Rivard (2005) identified various risk factors associated with IT outsourcing and for each risk factor, measures were either identified in the literature or were developed based on the expert advice. 
The ISM is a powerful technique, which can be applied to various fields where the complex issues or systems are to be handled. The ISM has been utilized in the literature (Singh et al., 2003, Raj et al., 2008, Faisel et al., 2006a). Singh et al. (2003) have used the ISM approach in the implementation of knowledge management in engineering industries. Faisel et al. (2006a) have utilized the ISM methodology in information risk management in supply chains. Raj et al. (2008) have analyzed the barriers in the implementation of flexible manufacturing systems and have also quantify them using ISM and GTA based methods. Gerwin (1992) and Hayes (1991) have investigated the management of AMTs implementation. Tummala et al. (2011) have illustrated risk management in supply chain management process. Tixer (2002) has depicted various methodologies for risk analysis in AMTs. Yang et al. (2003) have focused on the trends in AMTs development but have not taken in to account the issue of risk management.

Thus, from the literature it is quite evident that researchers have not paid due attention for risks involved in AMTs, especially in a developing country like India. So, this forms the basis for the present research work. This research would provide a framework and readymade food for firms to make strategies to avoid the pitfalls and reap the strategic benefits of advanced technology implementation.

\section{Identification and ranking of the risk factors}

The main objective of the questionnaire survey in this study is to facilitate experts in developing a driving power of risks involved in AMTs adoption and implementation. The important risk factors are identified, based on the expert advice and literature review. The important risk factors identified based on the literature survey and expert opinion stated and explained as under:

\section{Table 1}

Risk titles with their sources

\begin{tabular}{|c|c|c|}
\hline S.No. & Risk title & Source/Reference \\
\hline 1 & Risk of improper management & Harland et al., 2003; Hallikas et al., 2004 \\
\hline 2 & Financial risk like investment period & Speckman et al., 2004 \\
\hline 3 & Risk of loss of market share & Faisel et al., 2006a \\
\hline 4 & Risk of macro-economic changes & Aven et al., 2007 \\
\hline 5 & Risk of disagreement, disputes \& litigations & Harland et al., 2003 \\
\hline 6 & $\begin{array}{l}\text { Risk of lack of knowledge about AMTs in the lead group and } \\
\text { personnel }\end{array}$ & Aven et al., 2007 \\
\hline 7 & Technological risk like maintenance & Expert opinion \\
\hline 8 & Risk of non availability of good vendors for hi tech equipments & Aven et al., 2007 \\
\hline 9 & Organizational risks like integration & Hallikas et al., 2004 \\
\hline 10 & $\begin{array}{l}\text { Circumstantial risk like change in govt. policy, laws and } \\
\text { regulations }\end{array}$ & Aven et al 2007 \\
\hline 11 & Risk of industrial development changes & Hua et al., 2005 \\
\hline 12 & Risk of reliability of AMTs & Expert opinion \\
\hline 13 & Risk of applicability & Hua et al., 2005 \\
\hline 14 & Risk of new technology development & Expert opinion \\
\hline 15 & Risk of failure & Hua et al., 2005 \\
\hline
\end{tabular}

- Risk of improper management: The management of the overall system is a vibrant issue and needs the focus of the researchers in the field of AMTs because of the reason that improper management may lead to big financial losses. The management should be in a style that all the resources are utilized to optimal limit (Harland et al., 2003, Hallikas et al., 2004). The complex hardware AMTs like FMS requires proper management so that the maximum benefit may be reaped. However, non availability of highly trained management personnel for the collaborative planning may increase the risk of improper management. The improper management may lead 
to difficulty in resource allocation, organizational adaptability, establishing milestones and making the employee's aware above the benefits of AMT's.

- Financial risk like investment period: This risk concerns with the economic aspects of AMT's. The adaption of AMT's into any organization may be done on the basis of cost justification (Raj et al., 2008). This is a fact that heavy investment is needed for the implementation of AMT's in any organization. This introduces the financial risk. The financial risk may increases with the increase in investment period. The AMTs adoption and implementation may require a very long investment period due to the length of the implementation process, which increases the risk (Speckman et al., 2004). The length of the investment period can be decreased by planning properly on the implementation procedure.

- Risk of loss of market share: As stated above that the AMTs adoption and implementation may require a very long investment period due to the length of the implementation process. In this transition process i.e shifting from traditional manufacturing system to AMTs, there is a risk of loss of market share in this transition (Faisel et al., 2006a). The new technology creates the doubt in the mind of the share holders, whether the newly adopted toll/technology will reap all the benefits or not. A firm does not want to lose their market share in implementation process of new technologies.

- Risk of macro-economic changes: The economic changes are dynamic in nature and are subject to change every day. Sometimes these changes are for a short time and sometime they are for a long period (Aven et al., 2007). These changes at global level affect the economy and progress of the whole world. So, there is a risk of change in the economy when the adoption and implementation of the AMTs, which takes a little long time for implementation. For example, the big economies affects globally, the most of the countries are affected by them. This may introduce the risk of changes in economy at the time of AMTs implementation.

- Risk of disagreement, disputes \& litigations: When there is a big change in a firm, there are risks of disagreement, disputes and litigation in the employees, especially among the workers. There is a doubt in minds of the employees that the newly adopted technology may lead to expulsion of the manpower, requires highly trained personnel etc. and hence leads to disagreement, disputes and litigations (Harland et al., 2003). The disagreement, disputes and litigations of the employees may lead to strikes and hence big losses for the firms.

- Risk of lack of knowledge about AMTs in the lead group and personnel: The new technologies are being developed everyday and there is a risk that the lead group and the personnel might not be having the latest update regarding a particular technology. This may create panic and may lead to serious problems (Aven et al., 2007). This risk can be minimized by providing the training to staff and lead group so that AMTs can be adopted effectively and maximum benefits can be drawn.

- Technological risk like maintenance: There are many technical risks associated with AMTs adoption like maintenance of the complicated hardware and software associated with the AMTs. The non availability of trained personnel for hi-tech equipments, complex hardware and software of AMTs may introduce the technological risk. The other technological risks may include reliability of AMTs, Applicability of AMTs and further development of the AMTs.

- Risk of non availability of good vendors for hi tech equipments: As new hardware and software takes time for being readily available, there arise the risk of non availability of vendors for hi-tech equipments in that geographical area where AMTs are to be brought up. Suppose the other risks are minimum at a particular geographical area but there is a risk of non 
availability of good vendors for hi tech equipments, it may create panic in the minds of the managers (Aven et al., 2007).

- Organizational risks like integration: The AMTs are new manufacturing modes, therefore requires integration with the old technologies and also with the new technologies among each other. There are very high chances that the newly adopted hardware is not compatible with the existing software and the adopted software is not compatible with existing hardware. Also, the software-software and hardware-hardware should be compatible with each other. The complete system has to work as integrated (Hallikas et al., 2004). Along with this, there is a risk of the lack of knowledge about AMTs in lead group and personnel.

- Circumstantial risk like change in govt. policy, laws and regulations: AMTs projects are constrained not only by internal resources but also by external resources. Many circumstantial factors can cause critical risks. Such external factors include laws, regulations. The circumstances like govt. policy, laws, regulations changes from time to time, therefore introduce a risk for the firm (Aven et al., 2007).

- Risk of industrial development changes:The industrial development brings up the new changes in the industrial scenarios. These changes may be social, economic, ecological and political in nature. Sometimes, these changes prove to be beneficial for a particular industry and sometime may lead to losses. The managers have to take care this risk element before processing for the implementation of AMTs (Meredith, 1987).

- Risk of reliability of AMTs: The benefits out of new and latest technologies can only be reaped after their implementation, which is a costly and time consuming affair and a particular technology may not be reliable for that particular technical, social, ecological and political system. This increases the risk in AMTs adoption and implementation. For example fully automated systems are more reliable in developed countries as compared to developing countries because of big setup costs and abundant availability of the manpower in developing countries.

- Risk of applicability: There is very less or no past experience related to the applicability of the AMTs because these are newly developed technologies. The particular technology may not be appreciably applicable for that particular technical, social, ecological and political system. This increases the risk of applicability in AMTs adoption and implementation (Hua et al., 2005).

- Risk of new technology development: The industrial development brings changes in the manufacturing world in particular and society in general. The new technologies are being developed everyday and there is a risk that manufacturing technology adopted and implemented before sometime may become outdated and obsolete due to latest technology development (Hua et al., 2005). The money and time spend in implementing previous technology goes wasted. So, there is a risk of coming further new technology which can outdate the existing one.

- Risk of failure: Since the AMTs are quite new and latest manufacturing mode, therefore its theories and technologies are developed regularly; only experience can tell whether adopted technology will create benefits for a particular industry, society and ecology or not. The failure may be because of the internal as well as external reasons, therefore needs to be addressed in totality to minimize the risk of failure. The risk of failure may be the because of many reasons like failure of tool/technology adopted, lack of integration and non availability of trained personnel for hi-tech equipments (Hua et al., 2005). 
Risks mitigation in AMTs depends on a number of variables. A model depicting relationships among key variables would be of great value to the top management to delineate the focus areas. Further, there is also a need to understand the relation among the risks so that the management can understand the contribution of various classes of risks and whether their efforts to mitigate these risks are yielding the desired results or not. The impact of risks in AMTs adoption is dependent upon several sub-variables and thus the overall impact is the result of the individual impact of the sub-variables and their inter-relationships. It would facilitate the process of devising suitable strategies to alleviate these risks.

\section{Methodology on risks on AMTs}

The nation-wide questionnaire based survey and ISM approach has been utilized to generate the hierarchal model of the risk factors. The driving power and dependence power has been evaluated using ISM methodology. The detailed process has been illustrated in the following sections.

\subsection{Questionnaire based survey}

The framework has been proposed that uses interpretive structural modeling technique. For this, a nation-wide questionnaire based survey has been conducted which consists of fifteen questions, however there was only one question related to the risks in adoption of AMTs. The risks associated with the AMTs adoption and implementation along with their source has been presented in the Table 1. The respondents were asked to indicate the importance of fifteen risks on a five point likart scale. On this scale 1 and 5 corresponds to 'very low importance' to 'very high importance' respectively. The survey has been conducted of various Indian industries. The Table 2 shows the response of Indian industries for risks in AMTs adoption as extracted from the survey report. In this table, risks have been ranked on the basis of mean score evaluated on the basis of survey report. Now, a model depicting the relationship among the key risk factors would be of great value to the top management to delineate the focus areas. The ISM is most suitable approach for this situation because on the basis of the relationship between risks, an overall structure can be generated for system under consideration. The ISM technique is described as under:

Table 2

Response of Indian industries for risks in AMTs adoption (Extracted from survey report)

\begin{tabular}{llcc}
\hline S.No. & Risk Title & Average Score* & Rank \\
\hline 1 & Risk of improper management & 3.75 & 1 \\
2 & Financial risk like investment period & 3.67 & 3.48 \\
3 & Risk of loss of market share & 3.22 & 3 \\
4 & Risk of macro-economic changes & 2.97 & 4 \\
5 & Risk of disagreement, disputes \& litigations & 2.85 & 5 \\
6 & Risk of lack of knowledge about AMTs in the lead group and personnel & 2.80 & 6 \\
7 & Technological risk like maintenance & 2.64 & 7 \\
8 & Risk of non availability of good vendors for hi tech equipments & 2.59 & 8 \\
9 & Organizational risks like integration & 2.38 & 9 \\
10 & Circumstantial risk like change in govt. policy, laws and regulations & 10 \\
11 & Risk of industrial development changes & 2.12 & 11 \\
12 & Risk of reliability of AMTs & 2.05 & 12 \\
13 & Risk of applicability & 1.93 & 1.84 \\
14 & Risk of new technology development & 1.75 & 13 \\
15 & Risk of failure & & 14 \\
\hline$*$ on Likart scale 1 to 5 & & 15 \\
\hline
\end{tabular}

\subsection{ISM approach on risks in the implementation of AMTs}

The ISM is a powerful technique, which can be applied to various fields where the complex issues or systems are to be handled. The ISM have been utilized in the literature (Singh et al., 2003, Raj et al., 2008, Faisel et al., 2006a). Singh et al. (2003) have used the ISM approach in the implementation of 
knowledge management in engineering industries. Raj et al. (2008) have utilized ISM in the field of flexible manufacturing systems. Faisel et al. (2006a) have applied the ISM methodology in information risk management in supply chains. However, the various steps involved in the ISM on risks in the implementation of AMTs are described as under:

\section{- Step 1: Establishing the contextual relationship between the risks}

In this step, the variables affecting the system are listed, which can be objectives, actions and individuals etc. From the identified variables as shown in table 2, a contextual relationship is established, with respect to which the variables would be examined. The following symbols have been used to denote the relationship between various risks:

- V denotes that risk i influences the risk $\mathrm{j}$ or it is used for relation from risk $\mathrm{i}$ to $\mathrm{j}$.

- A is used to denotes that risk $\mathrm{j}$ influences the risk $\mathrm{i}$.

- $\mathrm{X}$ is used for bi-directional relations i.e risk $\mathrm{i}$ and $\mathrm{j}$ influences each other.

- $\mathrm{O}$ indicates that there is no relation between the two risks i.e $\mathrm{i}$ and $\mathrm{j}$ are unrelated.

- Step 2: Development of the structural self-interaction matrix (SSIM)

Development of SSIM involves indicating the pair wise relationship among the variables of the system under consideration. This has developed by discussing in a group of experts. On the basis of experts responses, the SSIM has been finalized and it is shown in table 3. The V, A, X and $\mathrm{O}$ are illustrated below:

- $\mathrm{V}$ is assigned to cell $(1,6)$ denotes that risk 1 influences the risk 6 or it is used for relation from risk 1 to 6 .

- A is assigned to cell $(2,3)$ is used to denotes that risk 3 influences the risk 2.

- $\mathrm{X}$ is assigned to cell $(12,14)$ is used for bi-directional relations i.e risks influences each other.

- is assigned to cell $(4,13)$ indicates that there is no relation between the two risks i.e 4 and 13 are unrelated.

\section{- Step 3: Development of the reachability matrix}

Reachability Matrix (RM) is developed from SSIM and the matrix is checked for transitivity. The transitivity is the basic assumption made in ISM. It states that if a variable A is related to B and B is related to C, then A is necessarily related to C. In this step, the SSIM is transformed into RM with following transformations as shown in Table 4:

- If the cell $(i, j)$ is assigned the symbol V in SSIM, then the cell $(i, j)$ entry becomes 1 and cell $(j, i)$ entry becomes 0 in the initial RM.

- If the cell $(i, j)$ is assigned the symbol A in SSIM, then the cell $(i, j)$ entry becomes 0 and cell $(j, i)$ entry becomes 1 in the initial RM.

- If the cell $(i, j)$ is assigned the symbol X in SSIM, then the cell $(i, j)$ entry becomes 1 and cell $(j, i)$ entry becomes 1 in the initial RM.

- If the cell $(i, j)$ is assigned the symbol O in SSIM, then the cell $(i, j)$ entry becomes 0 and cell $(j, i)$ entry becomes 0 in the initial RM.

- In the next step, the final RM is prepared by including the concept of transitivity and matrix is filled by inference as indicated by * in the final RM shown in Table 5.

\section{- Step 4: Partitioning the RM}

The final RM obtained in previous step is partitioned into different levels as shown in Table 6 . The reachability and antecedent set are found from the final reachability matrix as suggested by Warfield 1974 and Farris and Sage 1975. The reachability set consists of risk factor i itself and 
the other risk factors which are reachable from that risk factor $i$. For every 1 in the row of risk factor $i$, it has been contained in the reachabilty set. In the same way, antecedent set consists of risk factor $\mathrm{i}$ itself and risk factors which could reach the risk factor $i$. For every 1 in the column of risk factor $i$, it has been contained in the antecedent set. The common risk factors of the reachabilty set and antecedent set is presented in intersection set. If the intersection matrix and reachability matrix are same then the common risk factors have been labeled. The iterations are carried out until all risk factors have been labeled. These iterations are presented in Tables 6 and 7.

\section{- Step 5: Development of conical matrix}

The RM is then converted into conical form i.e most zero elements in upper diagonal half and most unitary elements in the lower half. This is generated by clubbing together the risk factors in the same level. In this way, the most 0's are above the diagonal of the conical matrix and most 1's are below the diagonal of the matrix as presented in Table 8. The drive power of a risk factor has been found by summing up the row elements and dependence power has been found by summing up the column elements of the conical matrix.

\section{- Step 6: Development of digraph}

Based on the relationships given in the reachability matrix, a directed graph is drawn and the transitive links are removed. The diagraph is presented in Fig. 1. In this digraph the top level risk factors are positioned at the top of the digraph and the second level risk factors are placed on the second level of the digraph and so on.

\section{- Step 7: Development of ISM model}

The diagraph is converted into ISM, by replacing variable nodes with statements as shown in Fig. 2.

\section{- Step 8: Check for conceptual inconsistency}

The conceptual inconsistency is removed by incorporating the transitivity and necessary modifications are made.

Table 3

Structural self-interaction matrix

\begin{tabular}{|c|c|c|c|c|c|c|c|c|c|c|c|c|c|c|}
\hline Risk & 15 & 14 & 13 & 12 & 11 & 10 & 9 & 8 & 7 & 6 & 5 & 4 & 3 & 2 \\
\hline 1 & $\mathrm{~V}$ & $\mathrm{~V}$ & $\mathrm{~V}$ & $\mathrm{~V}$ & $\mathrm{~V}$ & $\mathrm{O}$ & $\mathrm{V}$ & $\mathrm{V}$ & $\mathrm{V}$ & $\mathrm{V}$ & $\mathrm{V}$ & $\mathrm{O}$ & $\mathrm{V}$ & $\mathrm{V}$ \\
\hline 2 & $\mathrm{O}$ & $\mathrm{V}$ & $\mathrm{O}$ & $\bar{V}$ & $\mathrm{~V}$ & $\mathrm{~V}$ & $\mathrm{~V}$ & $\mathrm{~V}$ & $\mathrm{~V}$ & $\mathrm{O}$ & $\mathrm{V}$ & $\mathrm{V}$ & A & \\
\hline 3 & $\mathrm{~V}$ & $\mathrm{~V}$ & $\mathrm{O}$ & $\mathrm{V}$ & $\mathrm{O}$ & $\mathrm{V}$ & $\mathrm{V}$ & $\mathrm{V}$ & $\mathrm{O}$ & $\mathrm{V}$ & $\mathrm{V}$ & $\mathrm{A}$ & & \\
\hline 4 & $\mathrm{~V}$ & $\mathrm{~V}$ & $\mathrm{O}$ & $\mathrm{O}$ & $\mathrm{V}$ & $\mathrm{V}$ & $\mathrm{O}$ & $\mathrm{V}$ & $\mathrm{V}$ & $\bar{V}$ & $\mathrm{~V}$ & & & \\
\hline 5 & $\mathrm{~V}$ & $\mathrm{~V}$ & $\mathrm{~V}$ & $\mathrm{O}$ & $\mathrm{V}$ & $\mathrm{V}$ & $\mathrm{V}$ & $\mathrm{V}$ & $\mathrm{V}$ & $\mathrm{V}$ & & & & \\
\hline 6 & $\mathrm{~V}$ & $\mathrm{~V}$ & $\mathrm{~V}$ & $\mathrm{~V}$ & $\mathrm{~V}$ & $\mathrm{O}$ & $\mathrm{V}$ & A & $\mathrm{V}$ & & & & & \\
\hline 7 & $\mathrm{~V}$ & $\mathrm{~V}$ & $\mathrm{O}$ & $\mathrm{V}$ & $\mathrm{V}$ & $\mathrm{O}$ & $\mathrm{O}$ & $\mathrm{A}$ & & & & & & \\
\hline 8 & $\mathrm{~V}$ & $\mathrm{~V}$ & $\mathrm{O}$ & $\mathrm{O}$ & $\mathrm{V}$ & $\mathrm{V}$ & $\mathrm{V}$ & & & & & & & \\
\hline 9 & $\mathrm{~V}$ & $\mathrm{O}$ & $\mathrm{V}$ & $\mathrm{V}$ & $\mathrm{O}$ & $\mathrm{V}$ & & & & & & & & \\
\hline 10 & $\mathrm{X}$ & $\mathrm{O}$ & A & $\mathrm{O}$ & $\mathrm{O}$ & & & & & & & & & \\
\hline 11 & $\mathrm{~V}$ & A & $\mathrm{V}$ & $\mathrm{O}$ & & & & & & & & & & \\
\hline 12 & $\mathrm{~V}$ & $X$ & $\mathrm{O}$ & & & & & & & & & & & \\
\hline 13 & $\mathrm{X}$ & $\mathrm{X}$ & & & & & & & & & & & & \\
\hline 14 & $\mathrm{X}$ & & & & & & & & & & & & & \\
\hline
\end{tabular}


Table 4

Initial reachability matrix $(1,0)$

\begin{tabular}{lccccccccccccccc}
\hline Risks & 1 & 2 & 3 & 4 & 5 & 6 & 7 & 8 & 9 & 10 & 11 & 12 & 13 & 14 & 15 \\
\hline 1 & 1 & 1 & 1 & 0 & 1 & 1 & 1 & 1 & 1 & 0 & 1 & 1 & 1 & 1 & 1 \\
2 & 0 & 1 & 0 & 1 & 1 & 0 & 1 & 1 & 1 & 1 & 1 & 1 & 0 & 1 & 0 \\
3 & 0 & 1 & 1 & 0 & 1 & 1 & 0 & 1 & 1 & 1 & 0 & 1 & 0 & 1 & 1 \\
4 & 0 & 0 & 1 & 1 & 1 & 1 & 1 & 1 & 0 & 1 & 1 & 0 & 0 & 1 & 1 \\
5 & 0 & 0 & 0 & 0 & 1 & 1 & 1 & 1 & 1 & 1 & 1 & 0 & 1 & 1 & 1 \\
6 & 0 & 0 & 0 & 0 & 0 & 1 & 1 & 0 & 1 & 0 & 1 & 1 & 1 & 1 & 1 \\
7 & 0 & 0 & 0 & 0 & 0 & 0 & 1 & 0 & 1 & 0 & 1 & 1 & 0 & 1 & 1 \\
8 & 0 & 0 & 0 & 0 & 0 & 1 & 1 & 1 & 1 & 1 & 1 & 0 & 0 & 1 & 1 \\
9 & 0 & 0 & 0 & 0 & 0 & 0 & 0 & 0 & 1 & 1 & 1 & 1 & 1 & 0 & 1 \\
10 & 0 & 0 & 0 & 0 & 0 & 0 & 0 & 0 & 0 & 1 & 1 & 0 & 0 & 0 & 1 \\
11 & 0 & 0 & 0 & 0 & 0 & 0 & 0 & 0 & 0 & 1 & 1 & 0 & 1 & 0 & 1 \\
12 & 0 & 0 & 0 & 0 & 0 & 0 & 0 & 0 & 0 & 0 & 0 & 1 & 0 & 1 & 1 \\
13 & 0 & 0 & 0 & 0 & 0 & 0 & 0 & 0 & 0 & 1 & 0 & 0 & 1 & 1 & 1 \\
14 & 0 & 0 & 0 & 0 & 0 & 0 & 0 & 0 & 0 & 0 & 1 & 1 & 1 & 1 & 1 \\
15 & 0 & 0 & 0 & 0 & 0 & 0 & 0 & 0 & 0 & 1 & 0 & 0 & 1 & 1 & 1 \\
\hline
\end{tabular}

Table 5

Final reachability matrix $(1,0)$

\begin{tabular}{llllllllllllllll}
\hline Risks & 1 & 2 & 3 & 4 & 5 & 6 & 7 & 8 & 9 & 10 & 11 & 12 & 13 & 14 & 15 \\
\hline 1 & 1 & 1 & 1 & $1^{*}$ & 1 & 1 & 1 & 1 & 1 & $1^{*}$ & 1 & 1 & 1 & 1 & 1 \\
2 & 0 & 1 & $1^{*}$ & 1 & 1 & $1^{*}$ & 1 & 1 & 1 & 1 & 1 & 1 & $1^{*}$ & 1 & $1^{*}$ \\
3 & 0 & 1 & 1 & $1^{*}$ & 1 & 1 & $1^{*}$ & 1 & 1 & 1 & $1^{*}$ & 1 & $1^{*}$ & 1 & 1 \\
4 & 0 & 0 & 1 & 1 & 1 & 1 & 1 & 1 & $1^{*}$ & 1 & 1 & $1^{*}$ & $1^{*}$ & 1 & 1 \\
5 & 0 & 0 & 0 & 0 & 1 & 1 & 1 & 1 & 1 & 1 & 1 & $1^{*}$ & 1 & 1 & 1 \\
6 & 0 & 0 & 0 & 0 & 0 & 1 & 1 & 0 & 1 & $1^{*}$ & 1 & 1 & 1 & 1 & 1 \\
7 & 0 & 0 & 0 & 0 & 0 & 0 & 1 & 0 & 1 & 0 & 1 & 1 & $1^{*}$ & 1 & 1 \\
8 & 0 & 0 & 0 & 0 & 0 & 1 & 1 & 1 & 1 & 1 & 1 & $1^{*}$ & $1^{*}$ & 1 & 1 \\
9 & 0 & 0 & 0 & 0 & 0 & 0 & 0 & 0 & 1 & 1 & 1 & 1 & 1 & $1^{*}$ & 1 \\
10 & 0 & 0 & 0 & 0 & 0 & 0 & 0 & 0 & 0 & 1 & 1 & 0 & $1^{*}$ & $1^{*}$ & 1 \\
11 & 0 & 0 & 0 & 0 & 0 & 0 & 0 & 0 & 0 & 1 & 1 & 0 & 1 & $1^{*}$ & 1 \\
12 & 0 & 0 & 0 & 0 & 0 & 0 & 0 & 0 & 0 & $1^{*}$ & $1^{*}$ & 1 & $1^{*}$ & 1 & 1 \\
13 & 0 & 0 & 0 & 0 & 0 & 0 & 0 & 0 & 0 & 1 & $1^{*}$ & $1^{*}$ & 1 & 1 & 1 \\
14 & 0 & 0 & 0 & 0 & 0 & 0 & 0 & 0 & 0 & $1^{*}$ & 1 & 1 & 1 & 1 & 1 \\
15 & 0 & 0 & 0 & 0 & 0 & 0 & 0 & 0 & 0 & 1 & $1^{*}$ & $1^{*}$ & 1 & 1 & 1 \\
\hline
\end{tabular}

Note: $1^{*}$ entries are included to incorporate transitivity

Table 6

Iteration 1

\begin{tabular}{|c|c|c|c|c|}
\hline Risk & Reachability set & Antecedent set & Intersection set & Level \\
\hline 1 & $1,2,3,4,5,6,7,8,9,10,11,12,13,14,15$ & 1 & 1 & \\
\hline 2 & 2,3,4,5,6,7,8,9,10,11,12,13,14,15 & $1,2,3$ & 2,3 & \\
\hline 3 & $2,3,4,5,6,7,8,9,10,11,12,13,14,15$ & $1,2,3,4$ & $1,2,3,4$ & \\
\hline 4 & $3,4,5,6,7,8,9,10,11,12,13,14,15$ & $1,2,3,4$ & 3,4 & \\
\hline 5 & $5,6,7,8,9,10,11,12,13,14,15$ & $1,2,3,4,5$ & $1,2,3,4,5$ & \\
\hline 6 & $6,7,9,10,11,12,13,14,15$ & $1,2,3,4,5,6,8$ & 6 & \\
\hline 7 & $7,11,12,13,14,15$ & $1,2,3,4,5,7,8$ & 7 & \\
\hline 8 & $6,7,8,9,10,11,12,13,14,15$ & $1,2,3,4,5,8$ & 8 & \\
\hline 9 & $9,10,12,13,14,15$ & $1,2,3,4,5,6,8,9$ & 9 & \\
\hline 10 & $10,13,14,15$ & $1,2,3,4,5,6,8,9,10,12,13,14,15$ & $10,13,14,15$ & I \\
\hline 11 & $11,13,14,15$ & $1,2,3,4,5,6,7,8,11,12,13,14,15$ & $11,13,14,15$ & I \\
\hline 12 & $10,11,12,13,14,15$ & 1,2,3,4,5,6,7,8,9, 12,13,14,15 & $12,13,14,15$ & \\
\hline 13 & $10,11,12,13,14,15$ & $1,2,3,4,5,6,7,8,9,10,11,12,13,14,15$ & $10,11,12,13,14,15$ & I \\
\hline 14 & $10,11,12,13,14,15$ & $1,2,3,4,5,6,7,8,9,10,11,12,13,14,15$ & $10,11,12,13,14,15$ & I \\
\hline 15 & $10,11,12,13,14,15$ & $1,2,3,4,5,6,7,8,9,10,11,12,13,14,15$ & $10,11,12,13,14,15$ & I \\
\hline
\end{tabular}




\section{Table 7}

Iteration 2 to 7

\begin{tabular}{lllll}
\hline Risks & Reachability set & Antecedent set & Intersection set & Level \\
\hline 7 & 7 & $1,2,3,4,5,7,8$ & 7 & II \\
9 & 9 & $1,2,3,4,5,6,8,9$ & II & III \\
6 & 6 & $1,2,3,4,5,6,8$ & 9 & IV \\
8 & 8 & $1,2,3,4,5,8$ & 6 & V \\
5 & 5 & $1,2,3,4,5$ & 8 & VI \\
3 & $2,3,4$ & $1,2,3,4$ & 5 & VI \\
4 & 3,4 & $1,2,3,4$ & $2,3,4$ & VII \\
1 & 1 & 1 & 3,4 & 1 \\
\hline
\end{tabular}
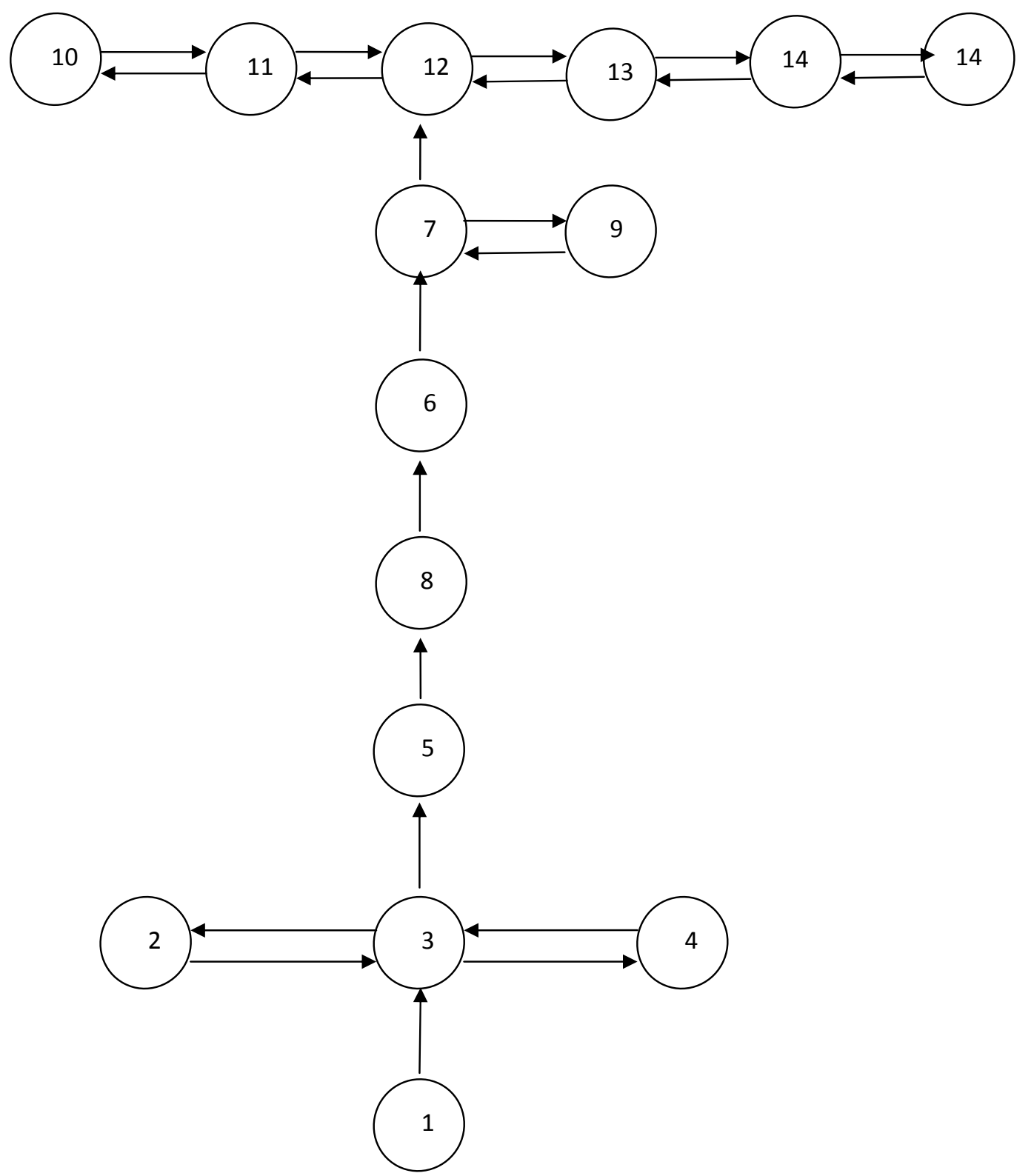

Fig. 1. Diagraph showing hierarchy of levels for risks 


\section{Table 8}

Conical matrix

\begin{tabular}{|c|c|c|c|c|c|c|c|c|c|c|c|c|c|c|c|c|}
\hline Risks & 10 & 11 & 12 & 13 & 14 & 15 & 7 & 9 & 6 & 8 & 5 & 2 & 3 & 4 & 1 & Drive power \\
\hline 10 & 1 & 0 & 0 & 1 & 1 & 1 & 0 & 0 & 0 & 0 & 0 & 0 & 0 & 0 & 0 & 4 \\
\hline 11 & 0 & 1 & 0 & 1 & 1 & 1 & 0 & 0 & 0 & 0 & 0 & 0 & 0 & 0 & 0 & 4 \\
\hline 12 & 1 & 1 & 1 & 1 & 1 & 1 & 0 & 0 & 0 & 0 & 0 & 0 & 0 & 0 & 0 & 5 \\
\hline 13 & 1 & 1 & 1 & 1 & 1 & 1 & 0 & 0 & 0 & 0 & 0 & 0 & 0 & 0 & 0 & 6 \\
\hline 14 & 1 & 1 & 1 & 1 & 1 & 1 & 0 & 0 & 0 & 0 & 0 & 0 & 0 & 0 & 0 & 6 \\
\hline 15 & 1 & 1 & 1 & 1 & 1 & 1 & 0 & 0 & 0 & 0 & 0 & 0 & 0 & 0 & 0 & 6 \\
\hline 7 & 0 & 1 & 1 & 1 & 1 & 1 & 1 & 0 & 0 & 0 & 0 & 0 & 0 & 0 & 0 & 6 \\
\hline 9 & 1 & 0 & 1 & 1 & 1 & 1 & 0 & 1 & 0 & 0 & 0 & 0 & 0 & 0 & 0 & 6 \\
\hline 6 & 1 & 1 & 1 & 1 & 1 & 1 & 1 & 1 & 1 & 0 & 0 & 0 & 0 & 0 & 0 & 9 \\
\hline 8 & 1 & 1 & 1 & 1 & 1 & 1 & 1 & 1 & 1 & 1 & 0 & 0 & 0 & 0 & 0 & 10 \\
\hline 5 & 1 & 1 & 1 & 1 & 1 & 1 & 1 & 1 & 1 & 1 & 1 & 0 & 0 & 0 & 0 & 11 \\
\hline 2 & 1 & 1 & 1 & 1 & 1 & 1 & 1 & 1 & 1 & 1 & 1 & 1 & 1 & 1 & 0 & 14 \\
\hline 3 & 1 & 1 & 1 & 1 & 1 & 1 & 1 & 1 & 1 & 1 & 1 & 1 & 1 & 1 & 0 & 14 \\
\hline 4 & 1 & 1 & 1 & 1 & 1 & 1 & 1 & 1 & 1 & 1 & 1 & 0 & 1 & 1 & 0 & 13 \\
\hline 1 & 1 & 1 & 1 & 1 & 1 & 1 & 1 & 1 & 1 & 1 & 1 & 1 & 1 & 1 & 1 & 15 \\
\hline Dependence power & 13 & 13 & 13 & 15 & 15 & 15 & 8 & 8 & 7 & 6 & 5 & 3 & 4 & 4 & 1 & \\
\hline
\end{tabular}
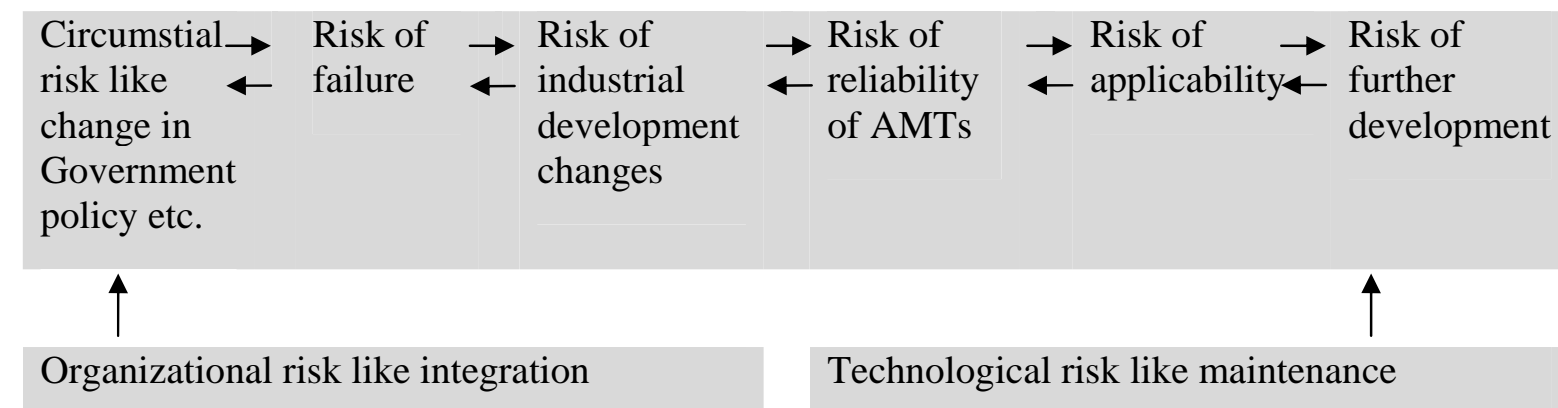

Technological risk like maintenance

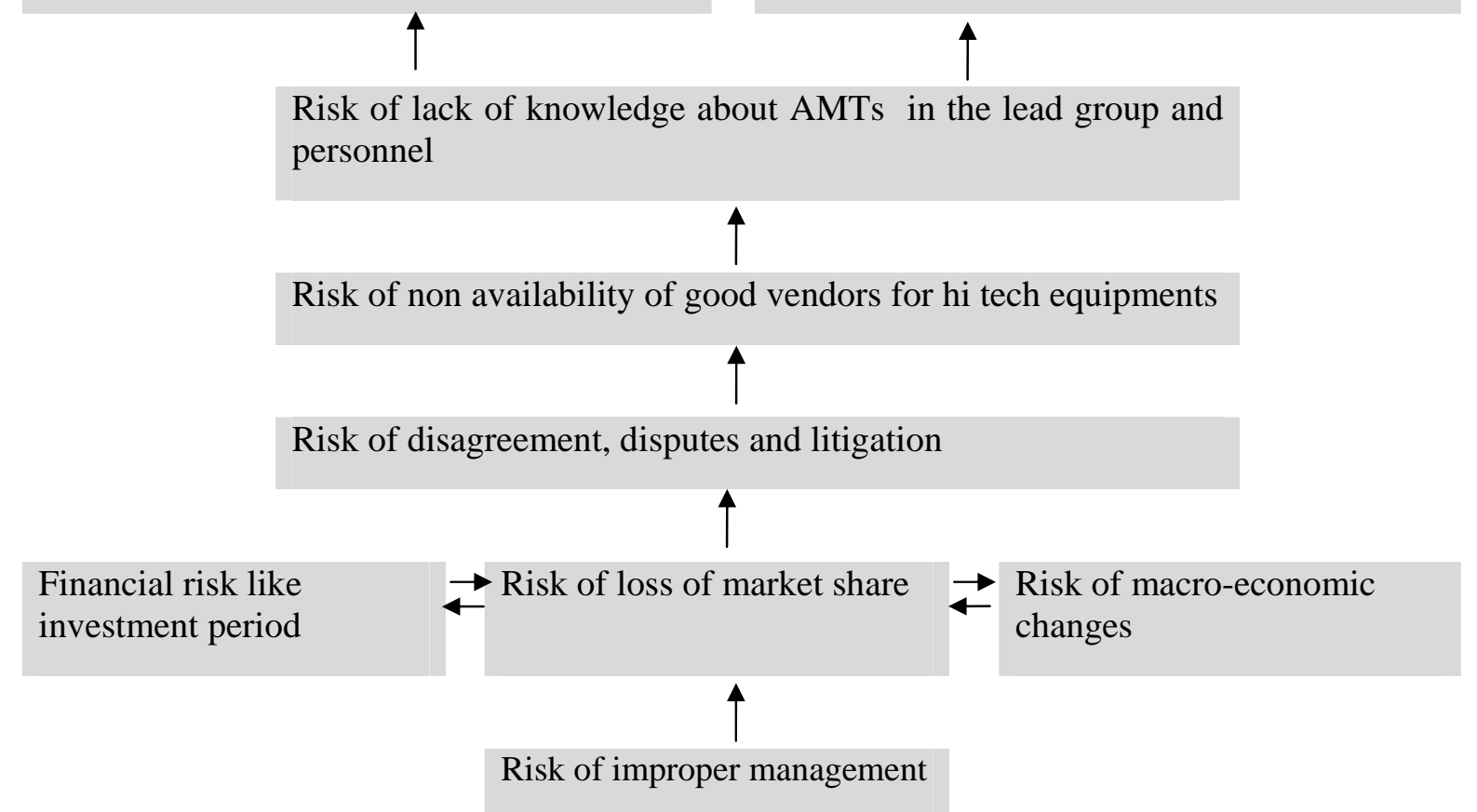

Fig. 2. ISM model depicting different levels of risks 


\subsection{MIMAC analysis}

Matrice d'Impact croises-multiplication appliqué an classment ( cross-impact matrix multiplication applied to classification) is abbreviated as MIMAC. The main purpose of the MIMAC analysis is to analyze the drive power and dependence of risk factors. This is done to find out the key factors that drive the system in various categories stated as under:

1. Autonomous risks: These risks are having weak drive power and weak dependence and lies in first quadrant as indicated in Fig. 3.

2. Linkage risks: These risks are having strong drive power and strong dependence and lies in third quadrant as shown in Fig. 3.

3. Dependent risks: These risks are having weak drive power and strong dependence and lies in second quadrant as illustrated in Fig. 3.

4. Independent risks: These risks are having strong drive power and weak dependence and lies in forth quadrant as indicated in Fig. 3.

Drive power

\begin{tabular}{|l|l|l|l|l|l|l|l||l|l|l|l|l|l|l|l|}
\hline 15 & 1 & & & & & & & & & & & & & & \\
\hline 14 & & & & 3 & & & & & & & & & 2 & & \\
\hline 13 & & & & 4 & & & & & & & & & & & \\
\hline 12 & & & IV & \multicolumn{2}{|l|}{$\begin{array}{l}\text { Independe } \\
\text { nt }\end{array}$} & & & & \multicolumn{2}{|l|}{ Linkage } & III & & & & \\
\hline 11 & & & & & & & & & & & & & & & 5 \\
\hline 10 & & & & & & 8 & & & & & & & & & \\
\hline 9 & & & & & & & 6 & & & & & & & & \\
\hline 8 & & & & & & & & & & & & & & & \\
\hline 7 & & & & & & & & & & & & & & & \\
\hline 6 & & & & & & & & 7,9 & & & & & & & 13,14 \\
\hline 5 & & & & & & & & & & & & & & & \\
\hline
\end{tabular}

Dependence power

\section{Discussion}

Fig. 3. Clusters of risks in AMTs implementation

The focus of manufacturing industries is to adopt regularly upcoming and latest systems but is afraid because of the risks associated in their adoption. The model developed in this research provides tool to the management to develop suitable strategies to minimize these risks.

The framework provide the opportunity to understand the focal areas that need more attention to minimize the risks in real time and AMTs can be frequently adopted on regular basis. Risk factors like risk of improper management, financial risk like investment period, risk of loss of market share and risk of macro-economic changes have strong driver power and less dependency. Therefore, these are strong drivers and can be treated as the key risk factors. They should be taken care on priority basis. Autonomous variables are weak drivers and weak dependents and do not have much influence on the system and can be planned accordingly. The risk factors like risk of industrial development 
changes, risk of reliability of AMTs, risk of applicability, risk of new technology development, risk of failure have less drive power and more dependency. This is because of the fact that a firm should have sufficient funds, only then it would think of latest tools/technology adoption and implementation. Also, financial management could be made by the finance department quite comfortably. Risk of lack of knowledge about AMTs in the lead group and personnel, technological risk like maintenance, risk of non availability of good vendors for hi tech equipments, organizational risks like integration have moderate drive power and moderate dependencies and should be handled accordingly.

\section{Conclusion}

The contribution of this paper is to propose an integrated framework for risks mitigation. The framework will guide the production managers to understand and manage risks related to AMTs adoption. The awareness of these risks and their driver and dependence power is important for risks mitigation since management can now focus on those variables which are of more strategic orientation. Along with the identification of risks, this paper has also presented an approach to categorize these risks. This would help the decision-makers to estimate the impacts of various risks and consequently develop suitable strategies to counter them. Therefore, to have a robust comprehensive risks mitigation policy in place, it is necessary for production managers to not only understand various risks mitigation variables but also the mutual relationships among them. The framework developed in this research has brought forth the following key issues: Risk factors like risk of improper management, financial risk like investment period, risk of loss of market share and risk of macro-economic changes have strong driver power and less dependency. Therefore, these are strong drivers and can be treated as the key risk factors. They should be taken care on priority basis. The risk factors like risk of industrial development changes, risk of reliability of AMTs, risk of applicability, risk of new technology development, risk of failure have less drive power and more dependency. Autonomous variables are weak drivers and weak dependents and do not have much influence on the system and can be planned accordingly.

\section{Limitations and scope for future work}

In the present study 15 risks were identified for their risk mitigation. More number of variables affecting information risks mitigation in AMTs can be identified to develop ISM. Experts help can be sought to develop the contextual relationships for the ISM model, which may have introduced some element of bias. Through ISM, a relationship model among the risks mitigation variables in an AMT can be developed which further can be extended by apply structural equation modeling (SEM) technique, commonly known as linear structural relationship approach to statistically corroborate the findings from ISM model. In present work, for the sake of simplicity the sub-systems within these each system of risks were not considered. This is one of the major limitations in the present work. So in future work the sub-systems may be considered and the impacts and interrelationships among the sub-system variables can be taken into account. In addition, the driving powers of the variables are based on the opinion of experts that again may have some bias. Further, it is the proposed that case studies may be carried out to understand risks behavior in actual practical settings.

\section{References}

Aven, T., Vinnem, J.E. \& Wiencke, H.S. (2007). A decision framework for risk management with application to the offshore oil and gas industry. Reliability Engineering and System Safety, 92, 433-48.

Bahli, B., \& Rivard, S. (2005). Validating measures of information technology outsourcing risk Factors. Omega, 33(2), 175-87. 
Beatty, C. (1990). Implementing advanced manufacturing technology. Business Quarterly, 55 (2), $46-$ 50.

Boer, H., Hill, M., \& Krabbendam, K. (1990). FMS implementation management: Promise and performance. International Journal of Operations and Production Management, 10 (1), 5-20.

Faisal, M.N., Banwet, D.K. \& Shankar, R. (2006a) Supply chain risk mitigation: modeling the Factors. Business Process Management Journal, 12(4), 535-52.

Faisal, M.N., Banwet, D.K. and Shankar, R .(2006b). Mapping supply chains on risk and customer sensitivity dimensions. Industrial Management \& Data Systems, 106 (6), 878-95.

Gerwin, D., \& Kolodny, H.( 1992). Management of Advanced Manufacturing Technology. Wiley, New York.

Hallikas, J., Karvonen, I., Pulkkinen, U., Virolainen, V.M. \& Tuominen.(2004). M., Risk management processes in supplier networks. International Journal of Production Economics, 90(1), 47-58.

Harland, C., Brenchley, R. \& Walker, H.( 2003). Risk in supply networks. Journal of Purchasing and Supply Management, 9(2), 51-62.

Hayes, R.H., \& Jaikumar, R. (1991). Requirements for successful implementation of new manufacturing technologies. Journal of Engineering and Technology Management, 7 (3-4), 169175.

Hua, L., Weiping, C., Zhixin, K., Tungwai, N., \& Yuanyuan, L. (2005). Fuzzy multiple attribute decision making for evaluating aggregate risk in green manufacturing. Tsinghua Science and Technology, 10(5) , 627-632.

Inman, R.A.( 1991). Flexible manufacturing systems: Issues and implementation. Industrial Management, 31 (4), 7-11.

Jharkharia, S. \& Shankar, R.( 2005). IT enablement of supply chains: understanding the barriers. Journal of Enterprise Information Management, 18 (1), 11-27.

Meredith, J.R. (1987). Implementing new manufacturing technologies: Managerial lessons over the FMS life-cycle. Interfaces, 17 (6), 51-62.

Meredith, J.R. (1988). The role of manufacturing technology in competitiveness: Peerless laser processors. IEEE Transactions on Engineering Management, 35 (1), 3-10.

Norrman, A. \& Jansson, U. (2004). Ericsson's proactive supply chain risk management approach after a serious sub-supplier accident. International Journal of Physical Distribution \& Logistics Management, 34 (5), 434-56.

Raj, T., Shankar, R., \& Suhaib M. (2007). A review of some issues and identification of some barriers in the implementation of FMS. International Journal of Flexible Manufacturing Systems, 19(1), 1-40.

Raj, T., Shankar, R., Suhaib, M., Garg, S., \& Singh, Y. (2008). An AHP approach for selection of advanced manufacturing system: a case study. International Journal of Manufacturing Research, 3(4), 471-498.

Singh, M.D., Shankar, R., Narain, R, \& Agarwal, A.(2003). An interpretive structural modeling of knowledge management in engineering industries. Journal of Advanced In Management Resources,1(1), 28-40.

Speckman, R.E. \& Davis, E.W. (2004). Risky business: expanding the discussion on risk and

the extended enterprise. International Journal of Physical Distribution \& Logistics management, 34 (5), 414-33.

Tang, C.S. (2006). Perspectives in supply chain risk management. International Journal of Production Economics, 103 (2), 451-88.

Tixer, J., Dusserre G, \& Salvi O.(2002). Review of risk analysis methodologies of industrial plants. Journal of Loss Prevention in Manufacturing Industries, 15, 291-303.

Tummala, R. \& Schoenherr, T. (2011). Assessing and managing risks using the supply chain management process. Supply Chain Management: An International Journal,1-25.

Yang S., \& Wu B. (2003). Trends in the development of advanced manufacturing technology. Chinese Journal of Mechanical Engineering, 39(10), 73-78. 